\title{
Prediction of Landing Gear Noise Reduction and Comparison to Measurements
}

\author{
Leonard V. Lopes* \\ Aeroacoustics Branch \\ NASA Langley Research Center, Hampton, Virginia, 23681
}

\begin{abstract}
Noise continues to be an ongoing problem for existing aircraft in flight and is projected to be a concern for next generation designs. During landing, when the engines are operating at reduced power, the noise from the airframe, of which landing gear noise is an important part, is equal to the engine noise. There are several methods of predicting landing gear noise, but none have been applied to predict the change in noise due to a change in landing gear design. The current effort uses the Landing Gear Model and Acoustic Prediction (LGMAP) code, developed at The Pennsylvania State University to predict the noise from landing gear. These predictions include the influence of noise reduction concepts on the landing gear noise. LGMAP is compared to wind tunnel experiments of a $6.3 \%$-scale Boeing 777 main gear performed in the Quiet Flow Facility (QFF) at NASA Langley. The geometries tested in the QFF include the landing gear with and without a toboggan fairing and the door. It is shown that LGMAP is able to predict the noise directivities and spectra from the model-scale test for the baseline configuration as accurately as current gear prediction methods. However, LGMAP is also able to predict the difference in noise caused by the toboggan fairing and by removing the landing gear door. LGMAP is also compared to far-field ground-based flush-mounted microphone measurements from the 2005 Quiet Technology Demonstrator 2 (QTD 2) flight test. These comparisons include a Boeing 777-300ER with and without a toboggan fairing that demonstrate that LGMAP can be applied to full-scale flyover measurements. LGMAP predictions of the noise generated by the nose gear on the main gear measurements are also shown.
\end{abstract}

\section{Introduction}

Noise has been a major concern in the aircraft industry for many years because of limitations placed on the allowable received noise by both the Federal Aviation Administration ${ }^{1}$ and international bodies. Over the past several decades, engine noise has been reduced significantly to levels comparable with airframe noise on approach. ${ }^{2}$ On landing, when the aircraft's engines are operating at reduced power and the flap system is in a high lift configuration, the airframe can be the primary noise contributor. ${ }^{3}$ Furthermore, some of NASA's next generation aircraft design concepts place the engines above the aircraft in an attempt reduce perceived noise through shielding. Reduction in engine noise requires that any further reduction in total aircraft noise must come from an equivalent reduction in airframe noise. ${ }^{4}$

Airframe noise is caused by any device on the aircraft excluding the engines and includes the slats, flaps, and landing gear. ${ }^{5,6}$ Even though each of these noise sources generate sound by different physical mechanisms, the noise generated is similar in amplitude but can have different noise directivity patterns. ${ }^{7}$ The noise from the flaps and slats is characterized by turbulent boundary layers passing over sharp trailing edges $^{8}$ and side edges. ${ }^{9}$ Trailing edge noise sources, like those from the flaps or slats, have been studied extensively ${ }^{10}$ and are the focus of ongoing research. ${ }^{11}$ The landing gear represent a significant challenge because of the non-uniform flow field under the wing ${ }^{12}$ and complex landing gear geometries with smallscale details that affect the high frequency noise. ${ }^{13}$ Interactions between the landing gear wake and the flap

*Research Aerospace Engineer; Member AIAA; leonard.v.lopes@nasa.gov 
system also contribute to the complicated noise signature. ${ }^{14}$ Predicting the interactions is difficult because the size and turbulence intensity of the landing gear wake is challenging to measure ${ }^{15}$ or calculate $^{16}$ due to the wake's dependence on landing gear geometry fidelity, wind-tunnel configuration and measurement technique, turbulence model, grid resolution, and Reynolds number effects.

Recently, under the 2005 Quiet Technology Demonstrator 2 (QTD 2) program, there has been an effort to measure the noise from landing gear using noise reduction concepts such as a toboggan fairing. ${ }^{17}$ Several noise reduction concepts were installed on a $26 \%$-scale, high-fidelity, Boeing 777 main landing gear in the Virginia Tech. Aeroacoustic Wind Tunnel. ${ }^{18}$ Measurements showed that installation of a toboggan fairing resulted in a reduction in noise in the higher frequencies, directly under the gear. ${ }^{19}$ Full-scale flyover measurements of a Boeing 777-300ER were unable to reproduce the noise reduction. Furthermore, experimental uncertainties caused by the differences in configuration and measurement processing techniques remain unresolved. ${ }^{20}$ Measurements of a similar landing gear geometry, a 6.3\%-scale detailed representation of the Boeing 777 main gear, performed in the NASA Quiet Flow Facility (QFF), which includes small-scale details such as tire treads and hoses, showed installation of the toboggan fairing resulting in a slight decrease in high frequency noise at a cost of increased low frequency noise. ${ }^{21}$ Other noise reduction techniques include those measured at the German-Dutch Wind tunnel - Large Low Speed Facility (DNW-LLSF) under the TIMPAN ("Technologies to IMProve Airframe Noise") program, a continuation of the SILENCER ("Significantly Lower Community Exposure to Aircraft Noise") program. ${ }^{22}$ These measurements include an Airbus A340 main gear in a "toe-down" configuration which resulted in a potential noise reduction of 7 EPNdB. ${ }^{23}$

The prediction of landing gear noise represents a significant challenge because of the small-scale features, complicated flow field, and potentially significant installation effects. In order to accurately predict the noise from a landing gear, all these influences must also be predicted accurately. The earliest prediction scheme, the Fink method ${ }^{24}$ developed in the late 1970's, is based on flight tests of full-scale aircraft to correlate the noise as a function of a few gross landing gear properties such as wheel diameter and oleo length. Because of the lack of measurements and analysis of flow fields at that time, this prediction method does not attempt to include the small-scale details or installation effects as separable predictions. Therefore, the Fink method is unable to predict the noise change due to a noise reduction concept, such as the toboggan fairing or gear alignment, as the gross landing gear features would remain the same. Another prediction scheme, the Guo method, ${ }^{25}$ separates the noise sources into 3 categories: the very-low, low, and high frequency ranges. Each frequency range has a simple directivity pattern and a list of complexity factors, which are calibrated to wind tunnel experiments. Recently, this method has been coupled with an external flow solution to include the effect of local flow conditions in the vicinity of the landing gear due to circulation around the wing. ${ }^{12}$ Although this method does reproduce some wind tunnel and fly-over measurements reasonably well, it does not provide the prediction of each landing gear component noise source as a separable prediction. Furthermore, it does not include many other effects such as reflection, scattering, or local flow due to the landing gear geometry. Since it is unable to include the installation effects and local flow conditions in the vicinity of the landing gear, it is unable to predict the influence of noise reduction concepts on installed landing gear noise. The Fink and Guo methods have been compared to measurements of noise from the 6.3\%-scale Boeing 777 main gear model performed in the QFF with moderate success. ${ }^{26}$ Another prediction scheme, the Smith and Chow method, ${ }^{27}$ uses a component based algorithm to compute the noise from the individual components of the landing gear; then the noise from each component is summed together to achieve the total noise source. Installation effects are included by direct modification of the directivity function, without knowledge of their actual physical mechanisms. Similar to the Guo method, predictions have been compared to a number of wind tunnel experiments and flight tests with moderate success. ${ }^{28}$ However, also similar to the Fink and Guo methods, the Smith and Chow method does not include interactions or installation effects as separable predictions, making prediction of the effect of noise reduction techniques very challenging.

A fourth prediction method has been developed at The Pennsylvania State University called the Landing Gear Model and Acoustic Prediction (LGMAP). ${ }^{29}$ LGMAP is a component based semi-empirical prediction scheme using an object oriented approach to acoustic prediction. The landing gear geometry is modeled as, in some cases, thousands of acoustic sources, each with their own flow input and acoustic output. The small geometric details of the landing gear are included in the noise prediction by directly including them in the landing gear representation. Including these small features has been shown to capture the noise level increase caused by an increase in landing gear geometry fidelity. ${ }^{30}$ Recently, aerodynamic and aeroacoustic interactions, such as scattering by the landing gear geometry, reflections by the wing, and local flow caused by the circulation of the wing, have been added to the scheme. ${ }^{31}$ 
This paper is outlined as follows. First, the LGMAP methodology is described. Then LGMAP is compared to measurements performed in the QFF. It is shown that LGMAP can predict the influence of the toboggan fairing and landing gear door on the radiated noise. After the model-scale comparison, LGMAP is compared to measurements performed during the flight tests of the QTD2 program. It is shown that LGMAP can predict the trend in noise change due to the toboggan fairing and the influence of nose gear noise on the landing gear noise spectrum.

\section{LGMAP Methodology}

LGMAP is a semi-empirical landing gear noise prediction scheme that has been developed at The Pennsylvania State University in conjunction with NASA Langley Research Center and The Boeing Company. ${ }^{29-31}$ LGMAP is a component based noise prediction scheme in some ways similar to the Smith and Chow method. However, this method differs in many key areas from those developed previously. The LGMAP method uses a small set of scalable acoustic elements to represent the physical components of the landing gear. The noise from each acoustic element is scaled by the component's characteristic length; large components generate predominantly low frequency noise while smaller components contribute mainly at higher frequencies. Each of the acoustic elements depends on the local flow properties, such as flow velocity and turbulence level. The local flow properties can be set to the uniform mean inflow into the landing gear region, or come from an independent flow prediction scheme such as CFD. This design allows a user to incorporate any external flow solution or approximation available; the user has the option to remove the dependence on an external flow solver or include a flow solution to increase accuracy of the noise prediction.

The central feature of LGMAP is a "toolbox" of acoustic elements (or objects), shown in Fig. 1. These include cylinder objects (these can be of any size and any cross section), edge objects (used for door edges, wing flaps, etc.), small fittings, and wheels. These objects are the building blocks that are used to construct the LGMAP representation of any landing gear configuration. Each object is a simplified geometric representation of the physical component modeled, which uses the local upstream environment as input to predict the noise. Engineering judgment is required to determine how to represent the complex landing gear components in terms of simple LGMAP acoustic elements. Large complex components that can potentially generate a broadband noise source can be modeled as a single broadband noise source or as one large low frequency noise source plus several smaller noise sources that generate noise at the higher frequencies. The total noise from the landing gear is simply the sum of noise generated by each of the individual acoustic elements.

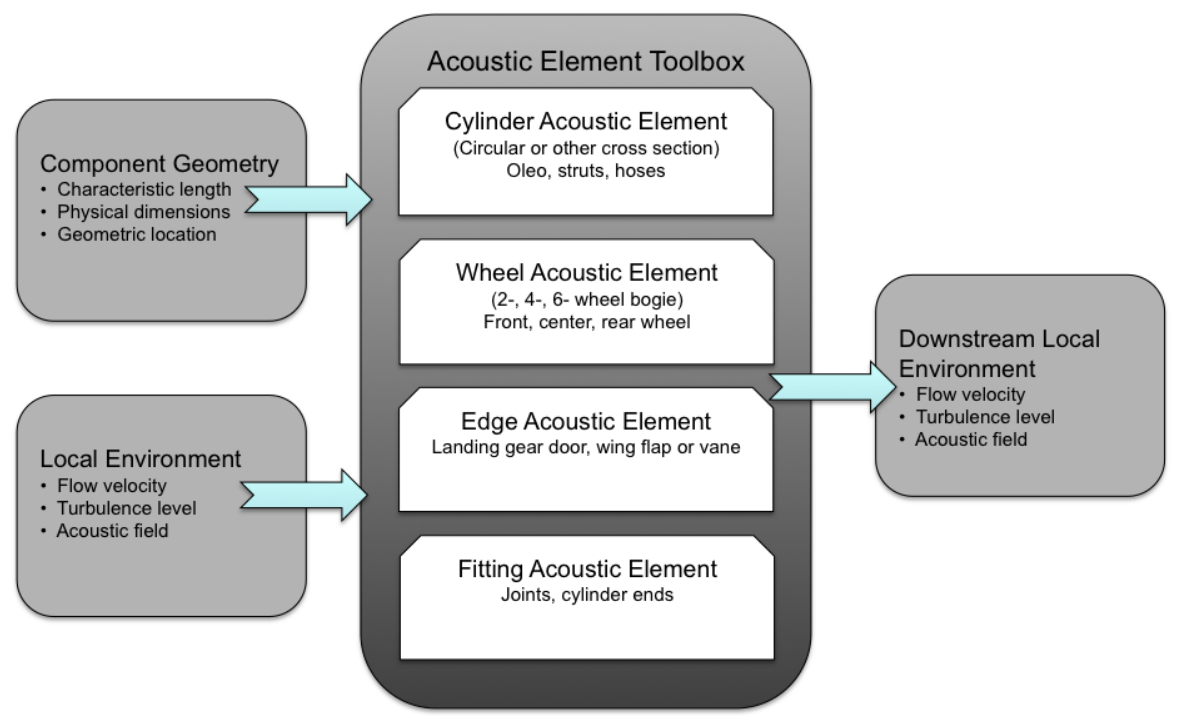

Figure 1. Schematic of the toolbox of acoustic elements implemented in LGMAP.

Following is a brief discussion of the details of the LGMAP prediction method. Since the acoustic 
elements have been presented in previous publications, ${ }^{29-32}$ their explanations are brief. Similar to the acoustic elements, the system of approximating the aerodynamic and aeroacoustic interactions involved in an LGMAP prediction have been presented previously ${ }^{31}$ and are not included here.

\section{A. Acoustic Elements}

Previous work on the LGMAP prediction system ${ }^{29,30}$ focused on models for the sound generated by different acoustic elements. LGMAP includes a few simple sound generating components, called acoustic elements, that are applied to a variety of components installed on the landing gear. By using the same acoustic element, whose inputs are functions of the properties of the individual component being modeled, the prediction system remains relatively simple while the complexity of the complete acoustic field is maintained. A brief description of the acoustic elements included in the LGMAP prediction system is given here.

\section{Cylinder Acoustic Element}

The primary acoustic element in the toolbox is the cylinder element. ${ }^{29}$ This acoustic element can be used to represent many pieces of the landing gear ranging from the oleo to small hoses. Cylinder acoustic elements in the LGMAP model are not intended to represent an isolated cylinder, but to instead account for the turbulent environment expected in the vicinity of the landing gear. Thus, the loading for the cylinder is modeled as broadband with a peak at the nominal shedding frequency of an isolated cylinder. The unsteady loads on each cylinder element of the landing gear are modeled using a non-dimensional loading spectrum, $F_{N D}$, as a function of Strouhal number, $S .{ }^{29}$ The same non-dimensional loading function is used for all elements in the LGMAP model. This spectrum is assumed to have a peak frequency, $S_{0}$, which is representative of the shedding Strouhal number for a cylinder in turbulent flow. The dimensional shedding frequency, and the dimensional fluctuating lift, $L^{\prime}$, and drag, $D^{\prime}$, forces are determined by scaling the loading for each cylinder element using the normal component of the local velocity, $V_{n}$, and the nominal cylinder diameter, $D$. The presence of incoming turbulence or non-uniformity in the cross-section is not modeled explicitly, but rather incorporated indirectly by a broadening of the loading spectrum. The non-dimensional loading spectrum function is given by,

$$
F_{N D}(S)=A S^{e-1}\left(B+S^{p}\right)^{-e}
$$

where,

$$
\begin{array}{lrl}
A=\left[\int_{S} S^{e-1}\left(B+S^{p}\right)^{-e}\right]^{-1} & B & =-S_{0}^{p}\left(\frac{e(1-p)-1}{e-1}\right) \\
L^{\prime}(S)=\frac{1}{2} \rho V_{n}^{2} D C_{l}^{\prime} F_{N D}(S) & D^{\prime}(S) & =\frac{1}{2} \rho V_{n}^{2} D C_{d}^{\prime} F_{N D}(2 S)
\end{array}
$$

Note that the integral of $F_{N D}(S)$ with respect to the Strouhal number, $S$, is unity and that the peak in the spectrum occurs at $S=S_{0}$. The remaining parameters, $A, B, e$, and $p$, are used to calibrate the model. The calibration of these parameters have been presented previously ${ }^{29}$ and are not included here.

\section{Wheel Acoustic Element}

For the LGMAP noise prediction the wheel is represented by a ring of source segments. ${ }^{32}$ The ring has a diameter equal to the tire diameter, and each segment in the ring has a diameter equal to the tire width. Although the flow around a tire has little similarity to flow around a ring, this model was calibrated as a simple model that can be used to provide noise radiation that is representative of a real wheel. It is also important to note that the segments used to make up the wheel ring do not all use the same loading spectrum. The spectrum and corresponding forces on each segment have been chosen so that this wheel model would have the same peak shedding frequency found in selected noise measurements performed in the QFF at NASA Langley. ${ }^{21,26}$

\section{Trailing Edge Acoustic Element}

Turbulent flow past sharp edges is known to produce trailing edge noise. LGMAP uses two methods for the prediction of the noise from a trailing edge. The first LGMAP trailing edge acoustic element can be 
used to predict the noise caused by a turbulent boundary layer interacting with a sharp trailing edge. The trailing edge noise elements use the theory of Brooks, Pope and Marcolini, ${ }^{10}$ as modified by Moriarty ${ }^{33}$ to allow for airfoils other than the NACA 0012. The program XFOIL ${ }^{34}$ is used to estimate the boundary layer thickness. LGMAP includes the ability to use any other boundary layer prediction method available. This semi-empirical scheme uses inputs such as airfoil cross section, angle of attack, boundary layer trip, turbulent inflow intensities and trailing edge bluntness. Using this as a callable function, LGMAP is able to predict the directivity of trailing edge noise.

The second trailing edge prediction method uses a modified Ffowcs Williams and Hall equation for trailing edge noise prediction. ${ }^{8}$ LGMAP $^{29}$ uses this method with an estimate of the landing gear wake properties in the vicinity of the trailing edge of a wing or flap to estimate the trailing edge noise increase caused by the presence of the landing gear. Reference 30 includes a detailed description of this process. In this manner, not only does LGMAP predict the landing gear noise from the landing gear itself, but also the increase in noise due to landing gear/flap interaction installation effects.

\section{B. Landing Gear Representation}

It is important to note that each landing gear component, such as the oleo, is not represented by a single acoustic source, but is instead comprised of many, sometimes hundreds, of individual acoustic sources. Each of these acoustic sources has it's own flow input and noise output which, when summed, is the total noise from the acoustic source. Figure 2(a) shows the baseline landing gear geometry measured in the $\mathrm{QFF}^{21}$ and Fig. 2(b) shows the LGMAP landing gear wire frame mesh representation of the same landing gear without the small-scale parts or dressing. Each color in the Fig. 2(b) represents a single LGMAP acoustic source. When including the dressing, the LGMAP representation of this landing gear includes over 6 thousand individual acoustic sources.

(a)

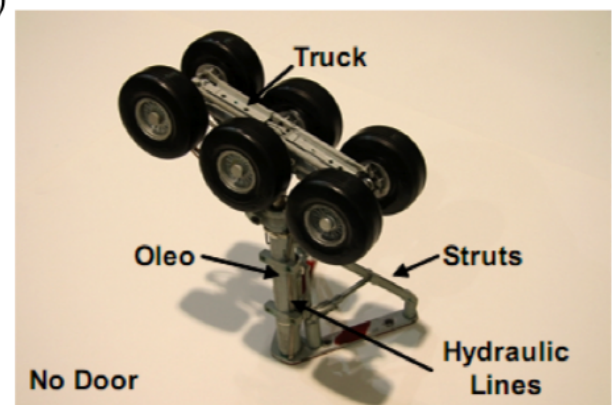

(b)

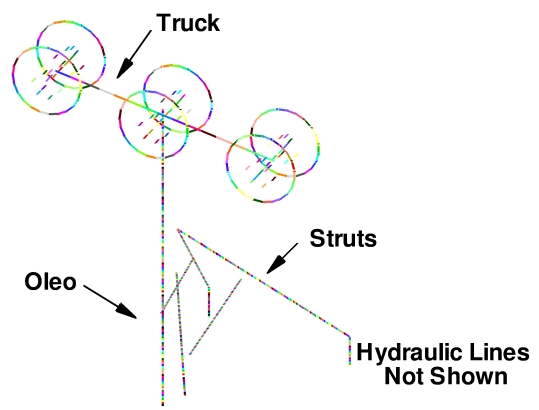

Figure 2. (a) Baseline landing gear tested in the Quiet Flow Facility (QFF) at NASA Langley. ${ }^{21,26}$ (b) LGMAP wire frame mesh of acoustic sources for the baseline Boeing $\mathbf{7 7 7}$ main gear configuration, dressing not shown. Each color represents a single acoustic source positioned on the geometry. LGMAP geometry of undressed Boeing 777 main gear contains 1129 individual acoustic sources and dressed baseline Boeing $\mathbf{7 7 7}$ main gear contains 6536 individual acoustic sources.

The LGMAP prediction methodology is unique in that each noise source in the LGMAP representation of the landing gear geometry can potentially be weighted with input from a CFD calculation or flow measurement. This allows the prediction method to predict the landing gear noise change due to a landing gear configuration change. However, CFD solutions or flow measurements are not always available. In the current analysis, the change in flow conditions caused by a change in landing gear configuration was estimated using engineering judgement. Then, by weighting the velocity impinging on the affected landing gear components, LGMAP is used to predict the change in noise. This is a first order estimate of the effect that changing the landing gear configuration has on the landing gear noise. Future prediction using the LGMAP prediction method to predict the change in noise from a landing gear configuration change should be coupled with some type of flow measurement or calculation. 


\section{QFF Comparisons}

The noise from a 6.3\%-scale high-fidelity Boeing 777 main gear was measured in the Quiet Flow Facility (QFF) at NASA Langley. ${ }^{21,26}$ The landing gear geometry was previously placed on a semi-span wing model that was measured in the Low Speed Aeroacoustic Facility (LSAF). ${ }^{15}$ The geometry contains many of the small-scale features of a full-scale landing gear to reproduce the noise in higher frequency ranges. The QFF experiment included both single microphone measurements and array measurements processed by the DAMAS source localization technique ${ }^{35}$ to map out the directivity pattern and spectral shape of the noise from the landing gear. The noise from four landing gear configurations was measured: a baseline configuration with and without the landing gear door present and a configuration with a toboggan noise reduction concept with and without the door present. For this paper, the results for three of these configurations, shown in Fig. 3, are used. Figure 4 shows a schematic of the landing gear installed in the tunnel with the measurement azimuthal and polar angles defined by $\phi_{e}$ and $\theta_{e}$ respectively.

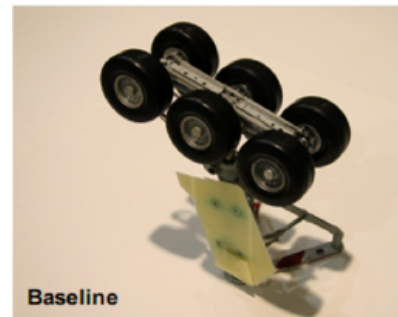

Figure 3. Landing gear geometry placed in the Quiet Flow Facility at NASA Langley. Includes with or without the door geometry and with or without toboggan fairing.

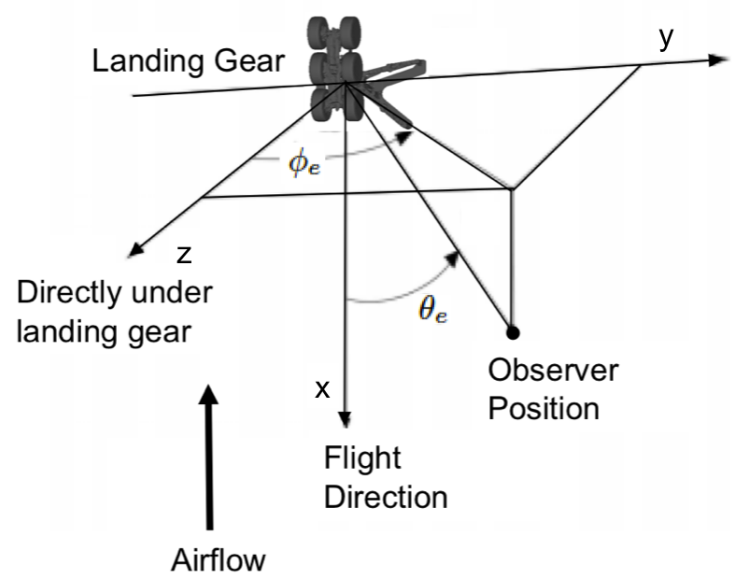

Figure 4. Quiet flow facility coordinate system for landing gear. The measurement azimuthal and polar angles are defined by $\phi_{e}$ and $\theta_{e}$ respectively. Microphone positions at a positive $\phi_{e}$ are on the non door-side of the landing gear, negative $\phi_{e}$ are at door-side positions. Microphone locations in the region of $0^{\circ}<\theta_{e}<90^{\circ}$ are at the forward positions and $90^{\circ}<\theta_{e}<180^{\circ}$ are at the aft microphone positions.

Figure 5 presents the single microphone noise measurements for the three landing gear configurations. The three configurations include the baseline configuration, baseline without the door, and baseline with the door and toboggan fairing. The peak in measured noise around $1000 \mathrm{~Hz}$ at all microphone locations is likely due to scattering from the side plates. ${ }^{36}$ Figure 5(a) through (c) show the effect of azimuthal variation in measurement location, while Figure 5(d) through (f) show polar variation on the measurements. The measurements exhibit slightly increased noise levels across most frequency ranges when the landing gear door is removed. The door acts like a flow alignment device, preventing symmetric shedding which is more intense than asymmetric shedding. Also, the door attributes to shielding for observers $\theta_{e}<0^{\circ}$, however more research is required to ascertain the influence of shielding on the noise. When the door is removed, the oleo experiences an increase in shedding which results in an increase in noise levels in the low- to mid-frequency range. The increased vortex shedding also causes increased interaction between the oleo and the nearby mid- 
and small-scale features. This may explain the increase in the mid- and high-frequency noise. Also shown in Fig. 5 are the measurements of noise from the gear with the toboggan fairing installed. Installation of the toboggan fairing reduces the high-frequency noise by shielding the smaller scale elements on the landing gear. However, the toboggan also acts like a bluff body, increasing the noise in the low- to mid-frequency range and altering the flow characteristics around the truck. This alteration may increases the flow velocity impinging on the wheels, hence increasing noise from the wheels.

LGMAP includes inputs that alter the incoming flow impinging on the sources to model the flow condition change caused by a configuration change. Ideally, these inputs are from flow measurement or computation. As these were unavailable, engineering judgement was used as estimated inputs prior to the prediction. These inputs were not altered afterward. To account for removal of the door, the LGMAP inputs were adjusted in the region of the oleo to account for its absence. Also, the trailing edge noise source caused by the door was removed. To account for installing the toboggan fairing, the flow velocities impinging on the components on the truck, excluding the wheels, were reduced while the flows impinging onto all 6 wheels were increased. Also included in the LGMAP prediction is a bluff body of approximately the same size as the nose of the toboggan fairing. Table 1 shows the modifications to LGMAP predictions used to estimate the influence of removing the door and installing the toboggan fairing.

Table 1. Modifications to landing gear configuration in the LGMAP predictions due to removing the landing gear door and installing the toboggan fairing.

\begin{tabular}{|l|l|c|}
\hline Configuration Change & Modified Components & Velocity Modifier \\
\hline \multirow{3}{*}{ Without Door } & Oleo and Nearby Dressing in Door Region & $+10 \%$ \\
& Support Struts in Oleo Region & $+5 \%$ \\
& Door Trailing Edge Noise Source Removed & \\
\hline \multirow{3}{*}{ With Toboggan } & Components on Truck, Excluding Wheels & $-5 \%$ \\
& All 6 Wheels & $+5 \%$ \\
& Addition of Toboggan Noise Source & \\
\hline
\end{tabular}

In sections III.A through III.C, LGMAP predictions are compared to the measurements for the three landing gear configurations shown in Fig. 3.

\section{A. Baseline Configuration}

Figure 6 shows the LGMAP predictions of the baseline landing gear geometry compared to the measurements at different emission angles. Also shown are the prediction breakdowns of the acoustic sources on the landing gear. LGMAP noise predictions agree well with the measurements across all emission angles and frequencies. The maximum difference between prediction and measurement occurs in Fig. 6(d) in the lower frequency range. This difference is approximately $5 \mathrm{~dB}$. Figures $6(\mathrm{a})$ through (c) show the measurements and predictions at different measurement azimuthal angles; Figs. 6(d) through (f) show the measurements and predictions at different polar angles. The predictions indicate that at the sideline locations, Figs. 6(a) and (c), the strut assembly, truck, hydraulic brackets, and hoses are all important noise contributors in the low, middle, high, and very high frequency ranges respectively. In the overhead positions, Figs. 6(b) and (e), the truck and hydraulic brackets are the primary noise sources in the low and high frequency range respectively. This is due to the radiation direction of the strut assembly and the shielding of the small-scale components due to the truck. The results for a variation in polar directivity angle, Figs. 6(d) and (f), show that at the forward and rear observer position, all components again become important factors.

\section{B. Without Landing Gear Door}

Figure 7 shows the LGMAP predictions, including component breakdown, compared to the measurements using the modifications in Table 1. Overall, the difference in both the measured and predicted noise between the baseline geometry and the baseline geometry with the door removed is minimal. The adjustment of the flow into the oleo prediction causes a slight increase in the noise from the oleo and nearby support struts due to an increase in vortex shedding. Also, the predicted noise in the high-frequency range, greater than 
(a)

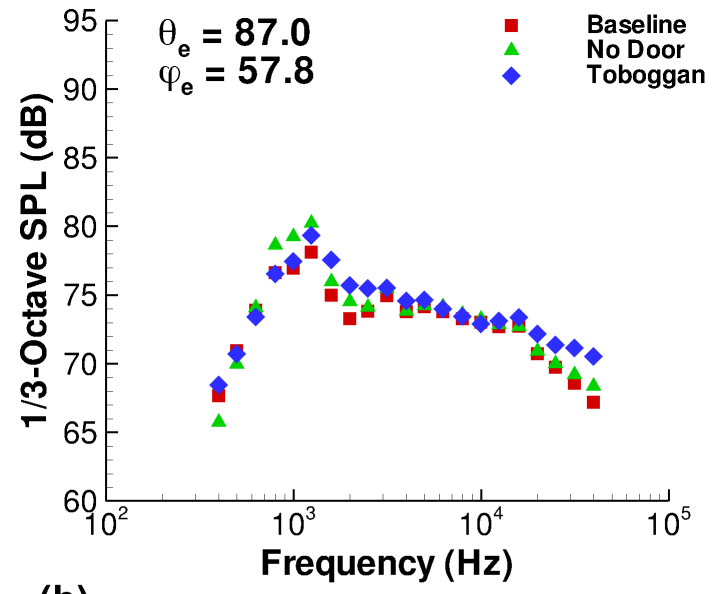

(b)

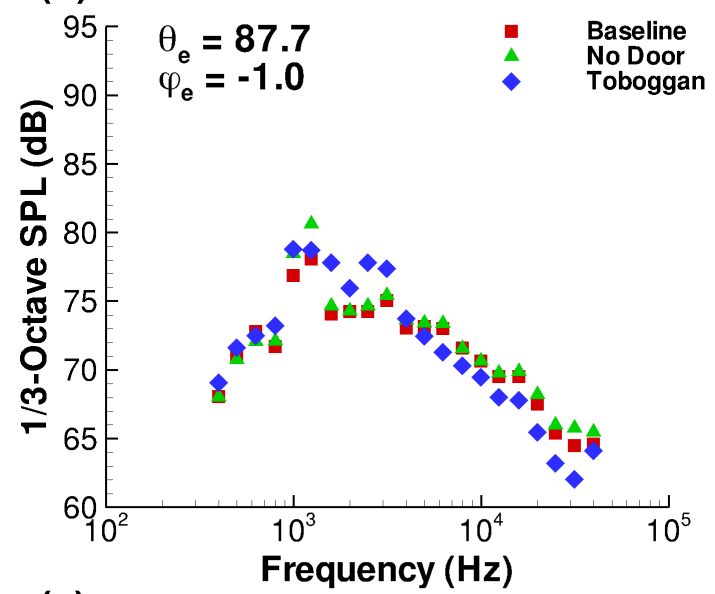

(c)

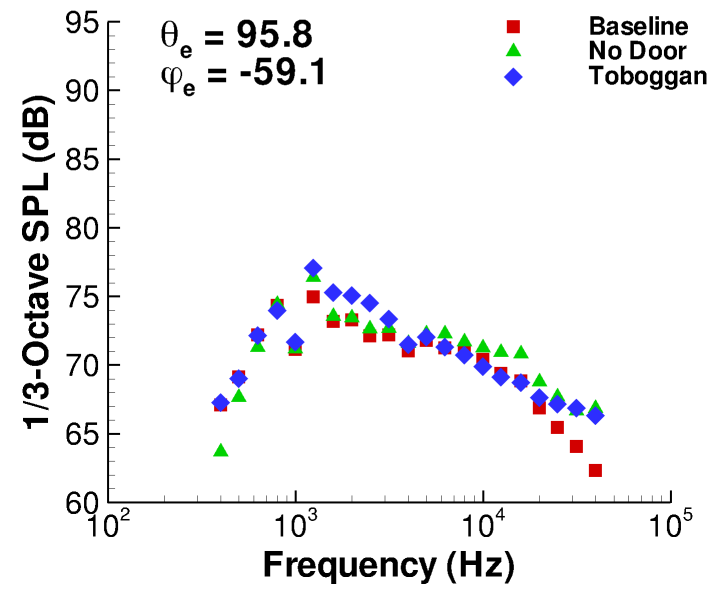

d)

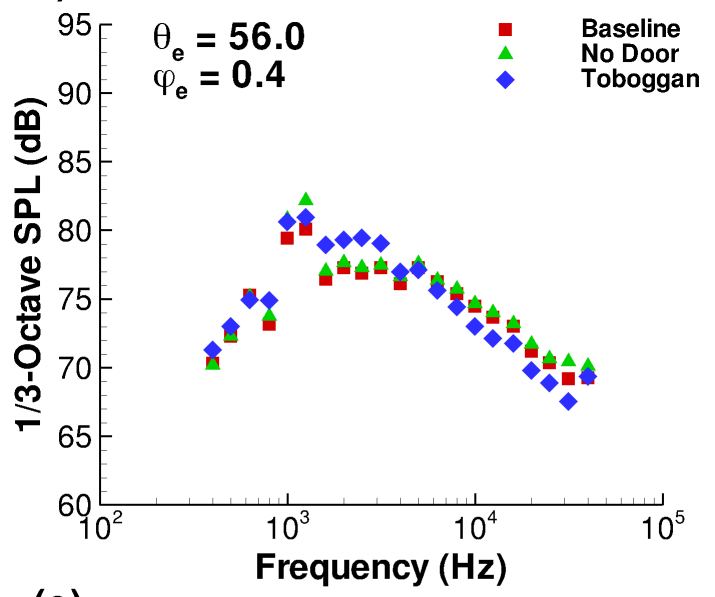

(e)

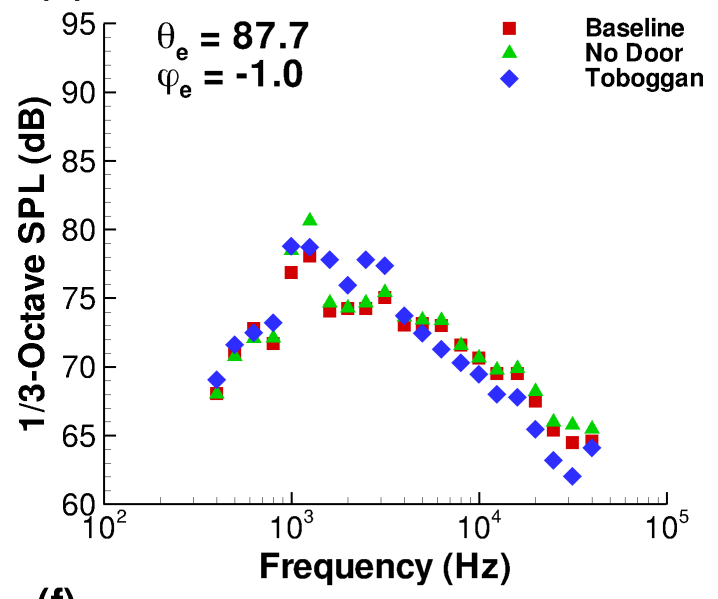

(f)

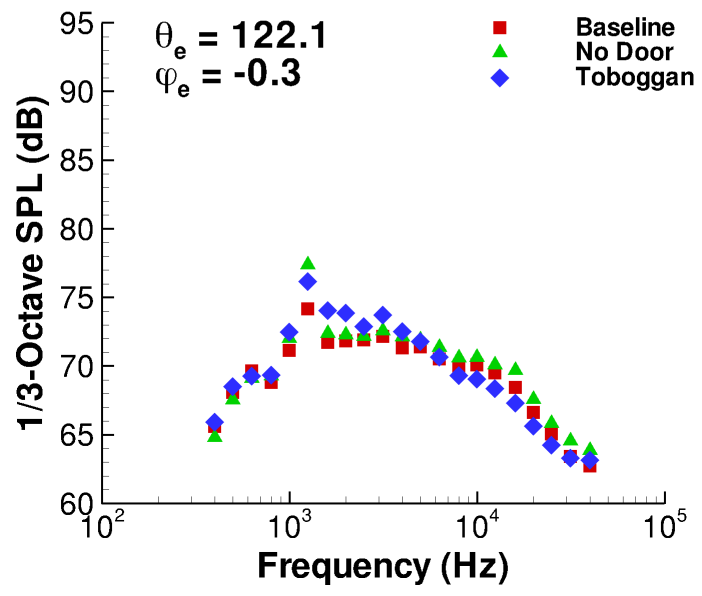

Figure 5. Single microphone noise measurements of three landing gear configurations performed in the Quiet Flow Facility (QFF) at NASA Langley. ${ }^{21,26}$ Measurements are shown at model-scale frequencies. Figures (a) through (c) are measurements across different azimuthal angle variations in measurement location, and Figs (d) through (f) are at different polar angle variations. 
(a)

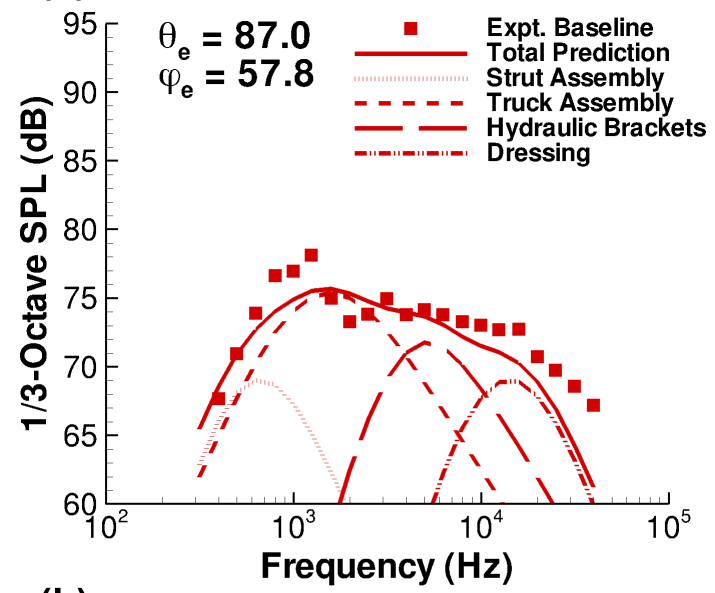

(b)

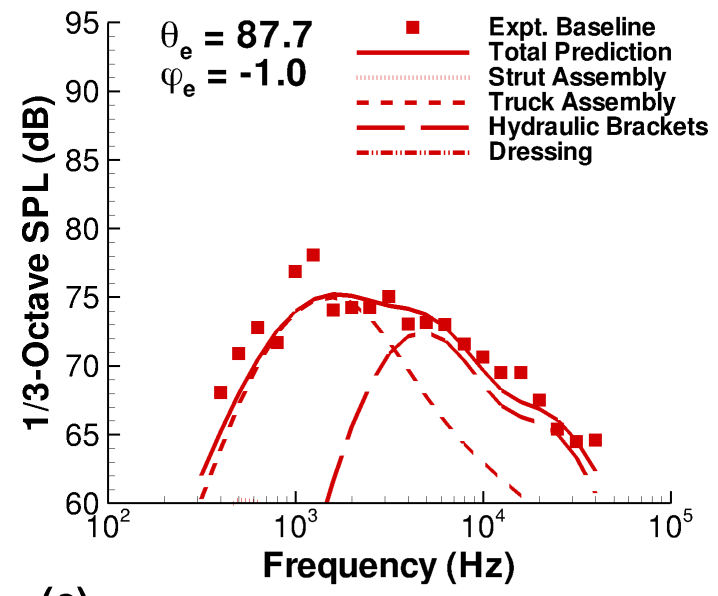

(c)

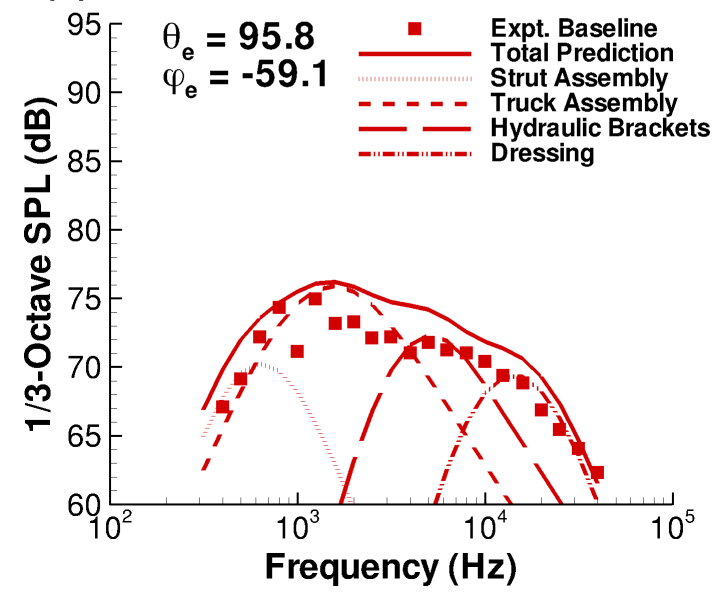

(d)

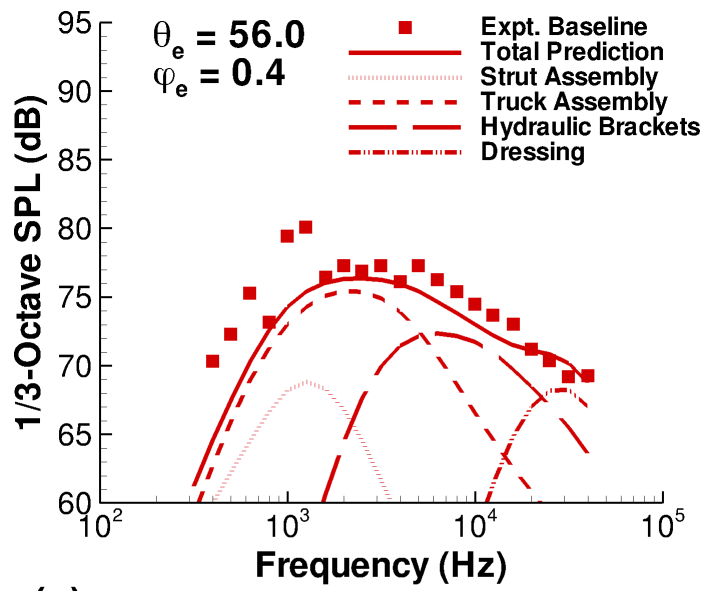

(e)

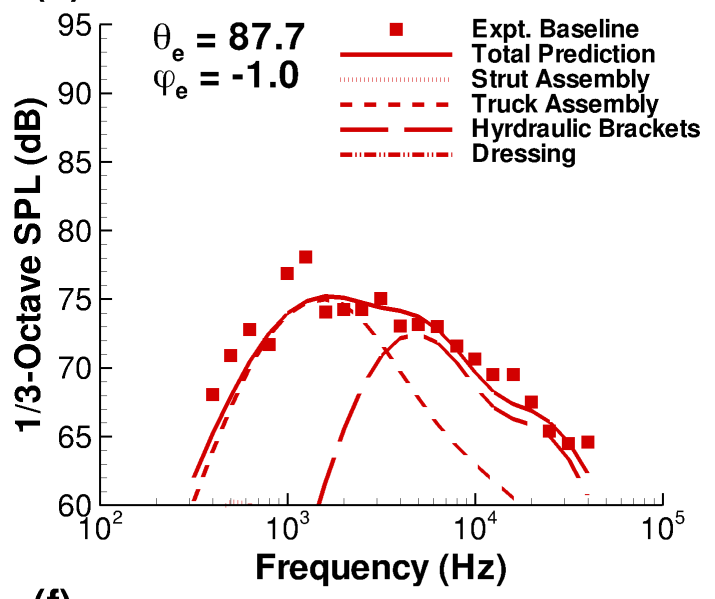

(f)

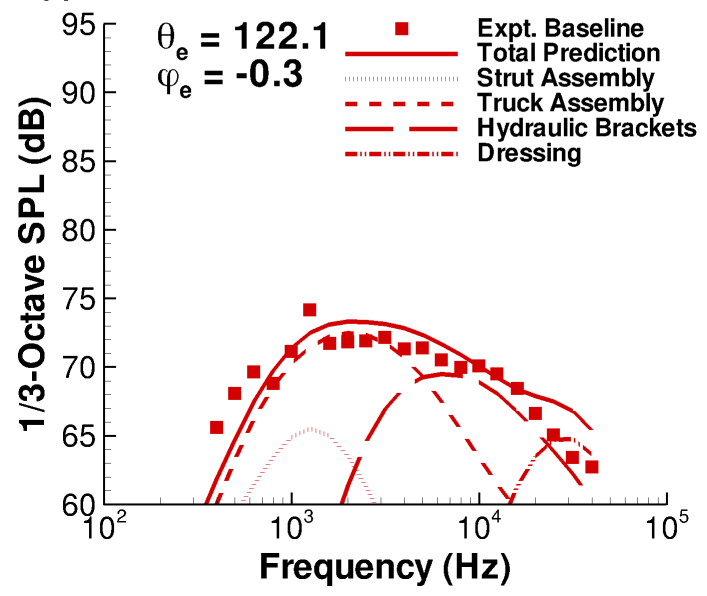

Figure 6. LGMAP predictions of noise from the baseline geometry compared to single microphone measurements performed in the Quiet Flow Facility (QFF) at NASA Langley. ${ }^{21}$ Figures (a) through (c) are for different azimuthal directivity angles and Figs. (d) through (f) are for different polar directivity angles. Symbols are measurements and lines are predictions. 
$5000 \mathrm{~Hz}$, is slightly increased due to an increase in flow velocity impinging on the small-scale features in the oleo region. At the overhead position, Fig. 7 (b) and (e), there is very little change in predicted noise due to the removal of the door. This is due to the directivity of the modified components. The oleo and struts directivity pattern is forward and to the side, while the noise from the truck dominates in the overhead position. The trailing edge noise source from the door was found to be much less than the other noise sources and therefore a difference in predicted noise due to the removal of the trailing edge is not seen in the predictions.

\section{Toboggan Fairing}

Figure 8 shows the predictions using the LGMAP modifications in Table 1 to account for the toboggan fairing, including a component breakdown, compared to the measurements performed in the QFF. As expected, installing the toboggan fairing on the landing gear geometry reduces the noise in the higher frequencies, however, the addition of the toboggan increases the predicted noise in the mid- to low-frequency range. This is seen across all microphone locations to a varying degree. In the microphone azimuthal directivity angles, Fig. 8(a) and (c), LGMAP is able to predict the noise increase of approximately $2 \mathrm{~dB}$ at the frequencies measured. At the higher frequencies, LGMAP predicts a noise decrease of approximately 1-2 dB while the measurements show a noise increase in the very high-frequency range. It is unclear why the measurements show a noise increase in the very high-frequency range due to the toboggan fairing but may be due to trailing edge noise from the toboggan fairing. At the overhead position, Fig. 8(b) and (e), LGMAP predicts the peak frequency of the noise increase at approximately $1000 \mathrm{~Hz}$ while the measurements show an increase at approximately $2500 \mathrm{~Hz}$. However, the noise increase in both the measurement and predictions is approximately $2-3 \mathrm{~dB}$. Both the predictions and measurements show a decrease in noise from $3000 \mathrm{~Hz}$ and higher of approximately 1-2 dB. At the different microphone polar locations, Fig. 8(d) and (f), both LGMAP predictions and QFF experiment show an increase in noise in the mid- to low-frequency range of approximately $2 \mathrm{~dB}$. Also, the LGMAP prediction show a noise decrease of approximately $1 \mathrm{~dB}$ at frequencies higher than 6000 $\mathrm{Hz}$ which matches the QFF experiments. Overall the LGMAP predictions match the QFF measurements well considering the simplicity of the modeling technique.

\section{QTD 2 Comparisons}

In the previous section, LGMAP geometries were compared to scaled measurements performed in the QFF. In this section, two of those geometries, with the same LGMAP parameters used when comparing to the QFF measurements, scaled to full-scale, are compared to measurements performed during the QTD2 flight test. The aircraft flown in the QTD2 flight test program was a Boeing 777-300ER at a forward flight velocity of 170 knots. $^{20}$ For all airframe measurements, both engines were set at idle-power to isolate the airframe noise signature. The QTD2 flight test measured the sound of the airframe with three main landing gear designs. These included a baseline landing gear configuration, a landing gear with wheels aligned to freestream flow velocity, and a landing gear with a toboggan fairing. The measurements also included two wing flap configurations: $0^{\circ}$ and $30^{\circ}$ flap angle. In the present analysis, the predictions will be compared to flush-mounted ground-based single microphone measurements from the aircraft with baseline main landing gear and baseline main gear with toboggan fairing installed. The noise from the nose gear is also predicted. For each case the flap angle is $0^{\circ}$, and the local flow velocity caused by circulation around the wing. ${ }^{31}$ The prediction methodologies for the main gear are also used for the nose gear and include a slightly increased inflow into the nose gear region. ${ }^{12}$ An infinite, perfectly reflecting wall is used as a first order approximation for the reflecting surfaces on the aircraft. Both main landing gear noise predictions include a reflecting wall to represent the wing, but the nose gear prediction does not approximate any reflections caused by the body.

The QTD2 measurements did not report absolute levels, but rather spectrum shapes and $\Delta \mathrm{dB}$. In the current comparison, the predictions have been adjusted in order to match the measured SPL at a frequency of $100 \mathrm{~Hz}$ for each spectrum shown. The predictions of the SPL from the entire aircraft are separated into five individual noise sources: nose gear, main gear strut, main gear truck, main gear hydraulic brackets, and main gear dressing. ${ }^{37}$ 
(a)

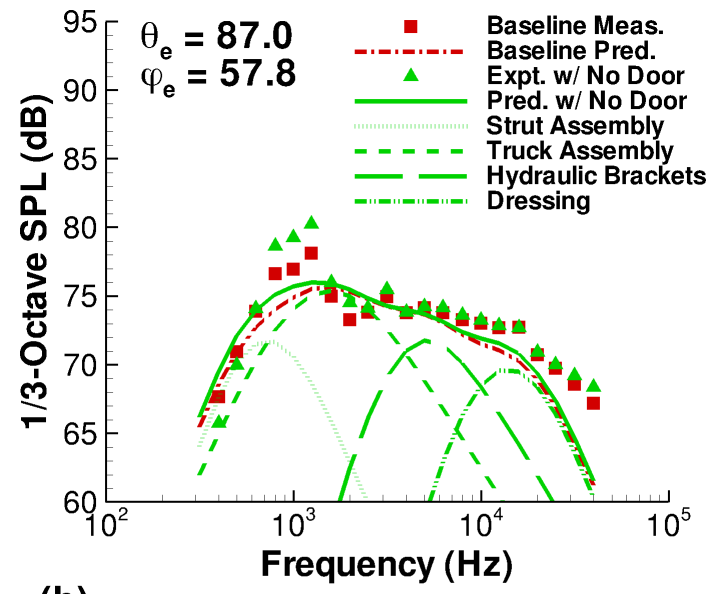

(b)

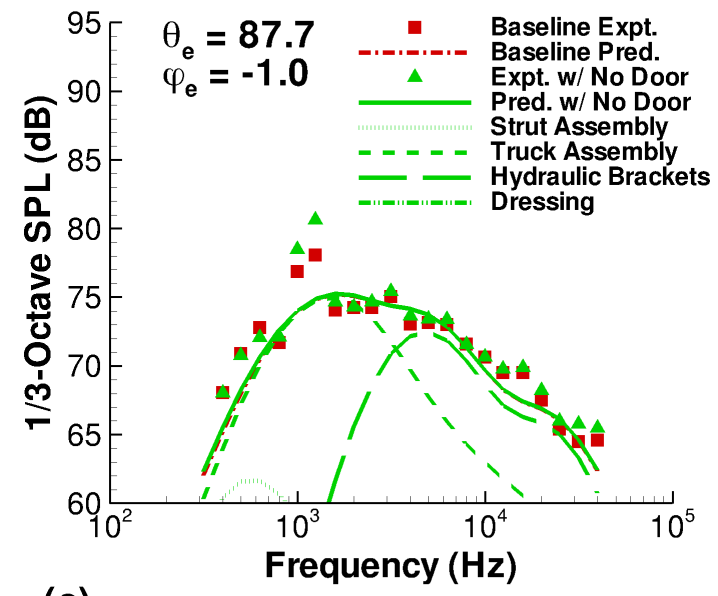

(c)

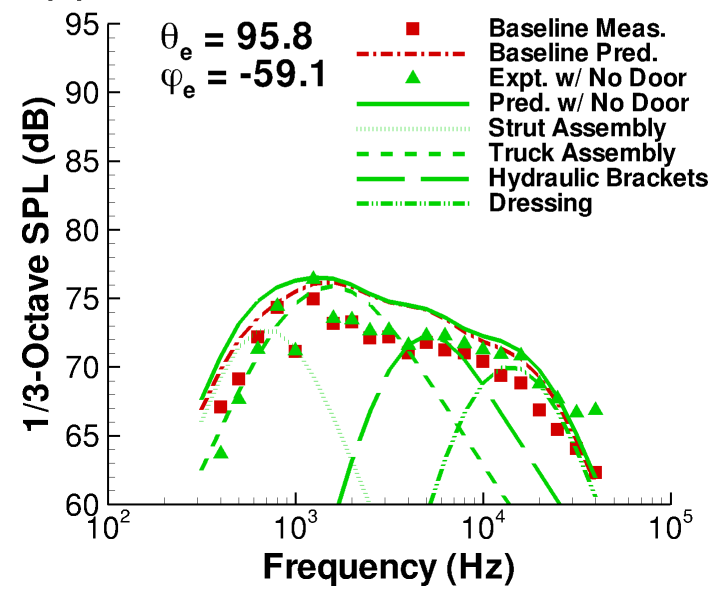

(d)

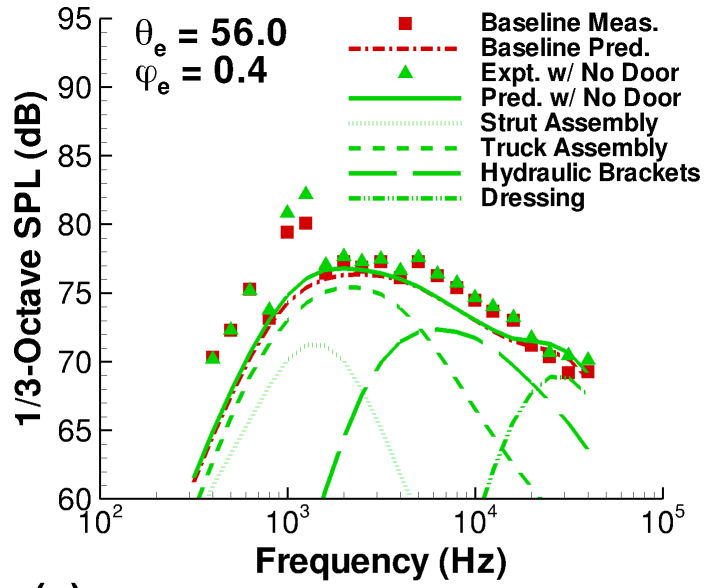

(e)

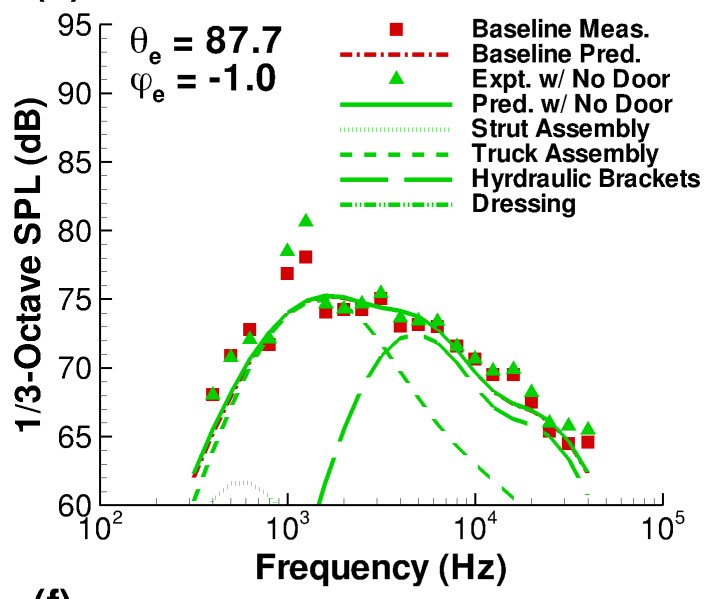

(f)

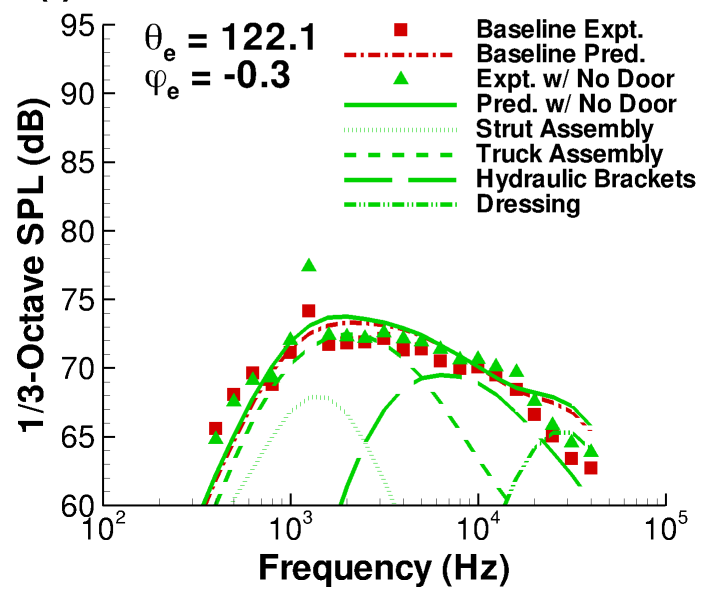

Figure 7. LGMAP predictions of noise from the baseline geometry with the door removed compared to single microphone measurements performed in the Quiet Flow Facility (QFF) at NASA Langley. ${ }^{21}$ Figures (a) through (c) show different azimuthal directivity angles and Figs. (d) through (f) show different polar directivity angles. Symbols are measurements and lines are predictions. 
(a)

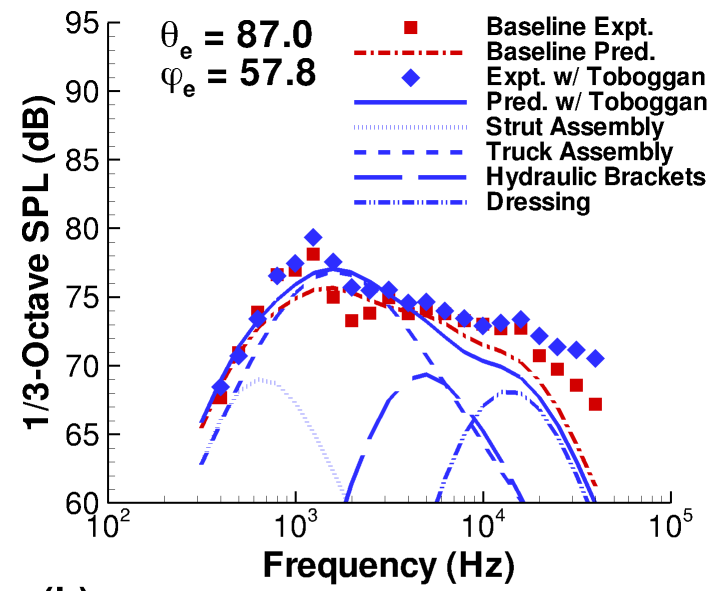

(b)

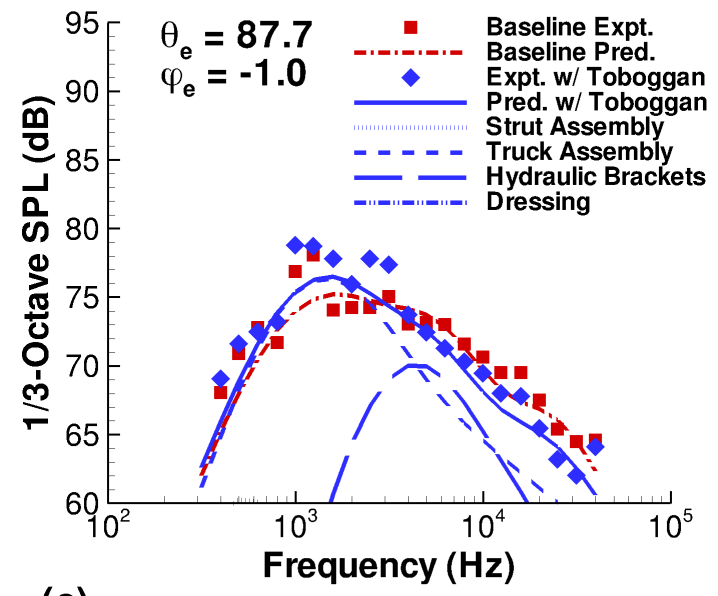

(c)

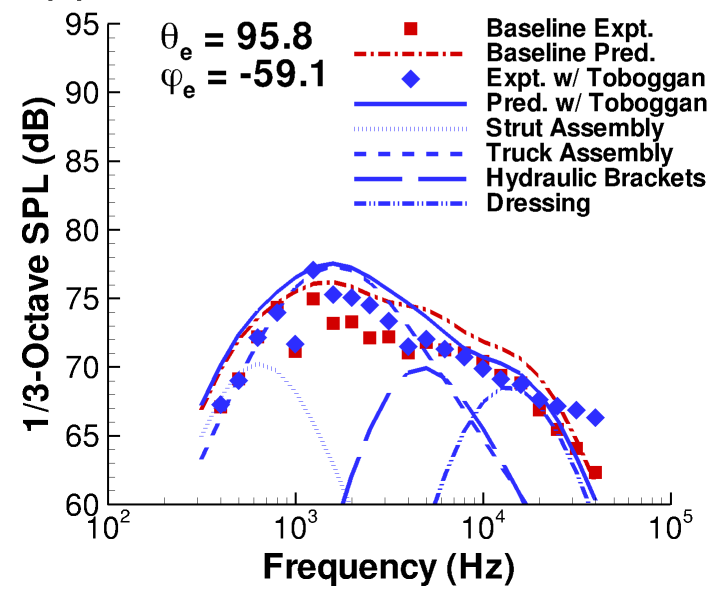

(d)

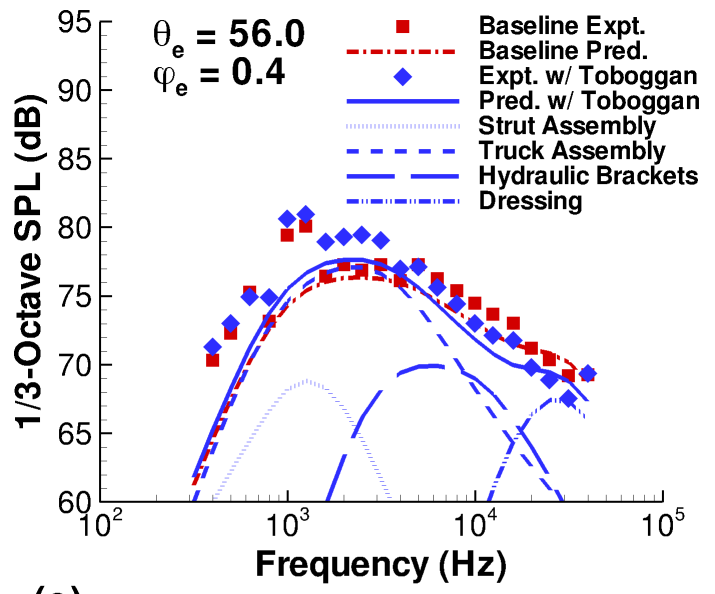

(e)

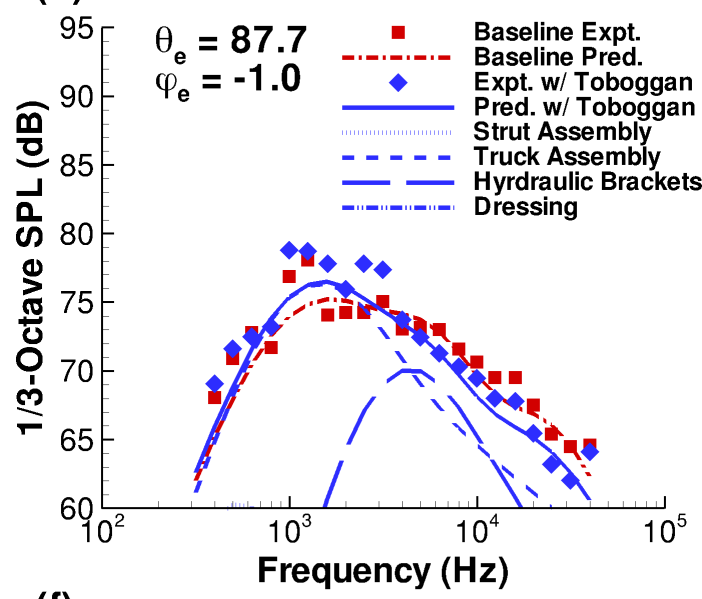

(f)

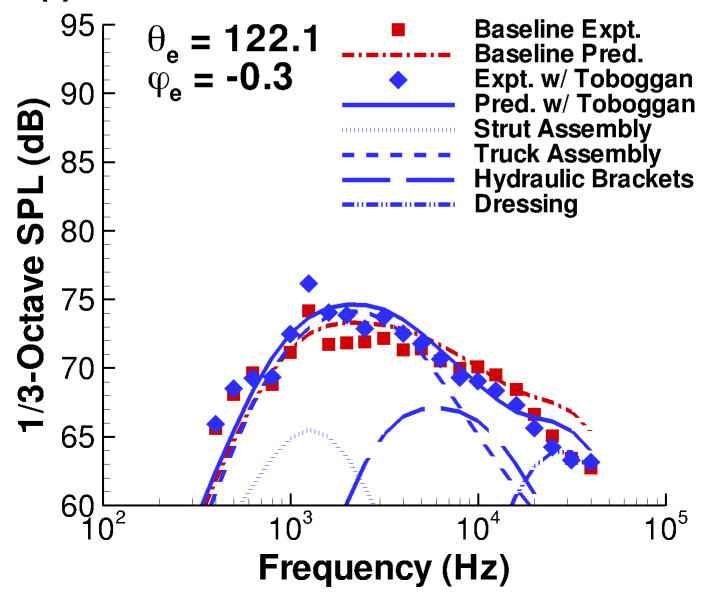

Figure 8. LGMAP predictions of noise from the baseline geometry with the toboggan fairing installed compared to single microphone measurements performed in the Quiet Flow Facility (QFF) at NASA Langley. ${ }^{21}$ Figures (a) through (c) show different azimuthal directivity angles and Figs. (d) through (f) show the results for different polar directivity angles. Symbols are measurements and lines are predictions. 


\section{A. Baseline Configuration}

Figure 9(a) shows the LGMAP predictions compared to the QTD2 measurements at a $60^{\circ}$ emission angle. The predicted spectrum shape for the complete aircraft in the low- and mid-frequency ranges, between onethird octave bands centered at frequencies 31.5 and $500 \mathrm{~Hz}$, matches very well to the flyover measurements, while the SPL at higher frequencies is underpredicted. The underprediction at the higher frequency ranges may be due to missing noise generating components in the landing gear prediction, other noise sources on the aircraft, or measurement inaccuracies. The predictions of individual noise sources show that all landing gear components contribute to the overall spectral shape. In the mid-frequency ranges, the nose gear is only a few decibels below the main gear noise prediction. Figure 9 (b) shows the predictions compared to the QTD2 measurements at an emission angle of $90^{\circ}$. For this emission angle, the predictions compare well with the measurements in the low- and mid-frequency range, between one-third octave bands centered at frequencies 31.5 and $630 \mathrm{~Hz}$. Similar to the comparison at an emission angle of $60^{\circ}$, the predictions for higher frequency ranges are underpredicted when compared to the measurements. And finally, Figure 9(c) shows the noise predictions compared to the QTD2 measurement at an emission angle of $140^{\circ}$. At this emission angle, the prediction of landing gear matches very well to measurements for all reported one-third octave bands. However, although the comparison between the prediction and measurements are very good, the measurements during the QTD2 flight test show that at this observer angle, other noise sources, including engine and airframe, may be equivalent to the landing gear noise. ${ }^{20}$
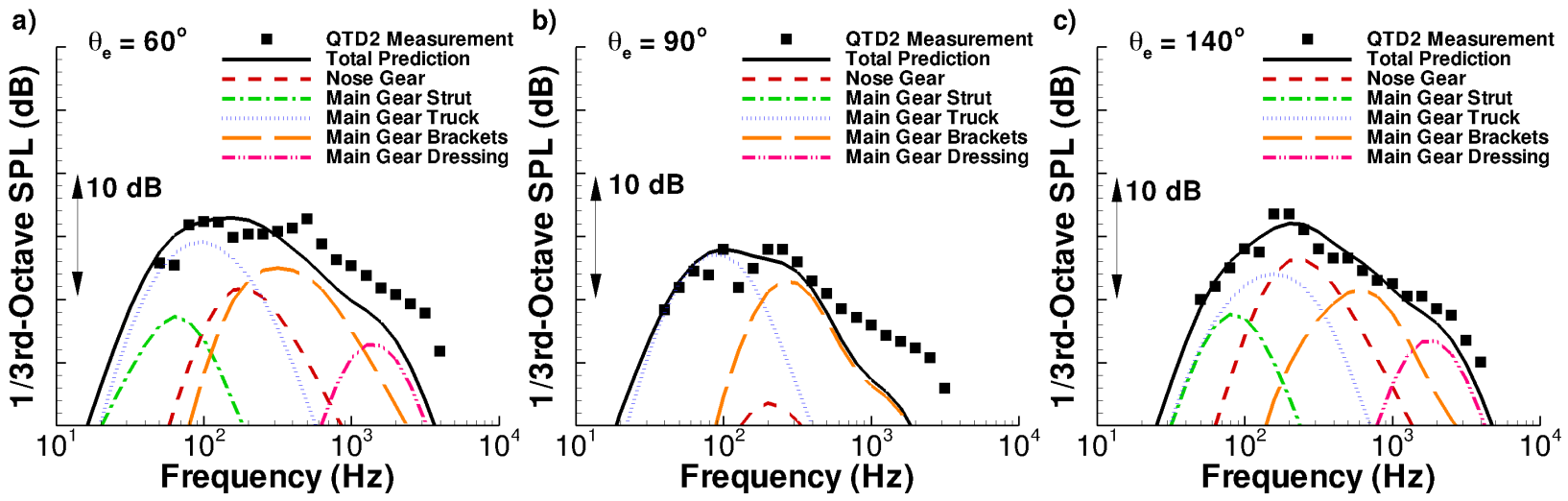

Figure 9. QTD2 flight measurements of baseline landing gear compared to LGMAP predictions at emission angles of (a) $60^{\circ}$, (b) $90^{\circ}$, and (c) $140^{\circ}$. The predicted SPL at a 1/3-octave center frequency of $100 \mathrm{~Hz}$ is (a) 76.2 $\mathrm{dB}$ at $60^{\circ}$, (b) $74.0 \mathrm{~dB}$ at $90^{\circ}$, and (c) $\mathbf{7 4 . 0} \mathrm{dB}$ at $140^{\circ}$. Symbols are measurements and lines are predictions.

\section{B. Toboggan Fairing}

The QTD2 measurements also included a toboggan faired landing gear similar to the one measured in the $\mathrm{QFF}^{21,26}$ and at Virginia Tech. ${ }^{18}$ Figure 10 shows the difference in the QTD2 measurements and LGMAP predictions between the baseline landing gear configuration and the landing gear with the toboggan fairing at 3 observer positions. Figure 10(a) shows the difference in measurements and prediction at the forward arc observer position. Both the measurements and predictions show an increase in noise in the low- to midfrequency range of approximately 2-3 dB. Also, both the measurements and predictions show a decrease in noise in the mid- to high-frequency range of a maximum of approximately $1 \mathrm{~dB}$. Considering the simplicity of the model and the complicated noise source, the predictions match very well to the measurements (given reasonable inputs, i.e. velocities). Figure 10(b) shows the difference in measurements and predictions at the overhead observer position. At this microphone location the predictions and the measurements show the same trend with an increase in the lower frequencies and a decrease in the higher frequencies. However, LGMAP overpredicts the noise reduction in the high-frequencies by as much as $2 \mathrm{~dB}$. This may be due to the other noise sources on the aircraft, such as the engine or airframe, masking the noise reduction caused by the toboggan or the prediction model. And finally, Figure 10(c) shows the difference in measurements and predictions at the rear observer arc. At this position, both the measurements and predictions again show an increase in noise at the low- to mid-frequency range of the same magnitude. In the mid- to high-frequency 
range the predictions show a decrease in noise which is not seen in the measurements. Again, this may be due to the measurements being corrupted by other noise sources on the aircraft or the predictions not capturing the sources and/or directivities accurately.
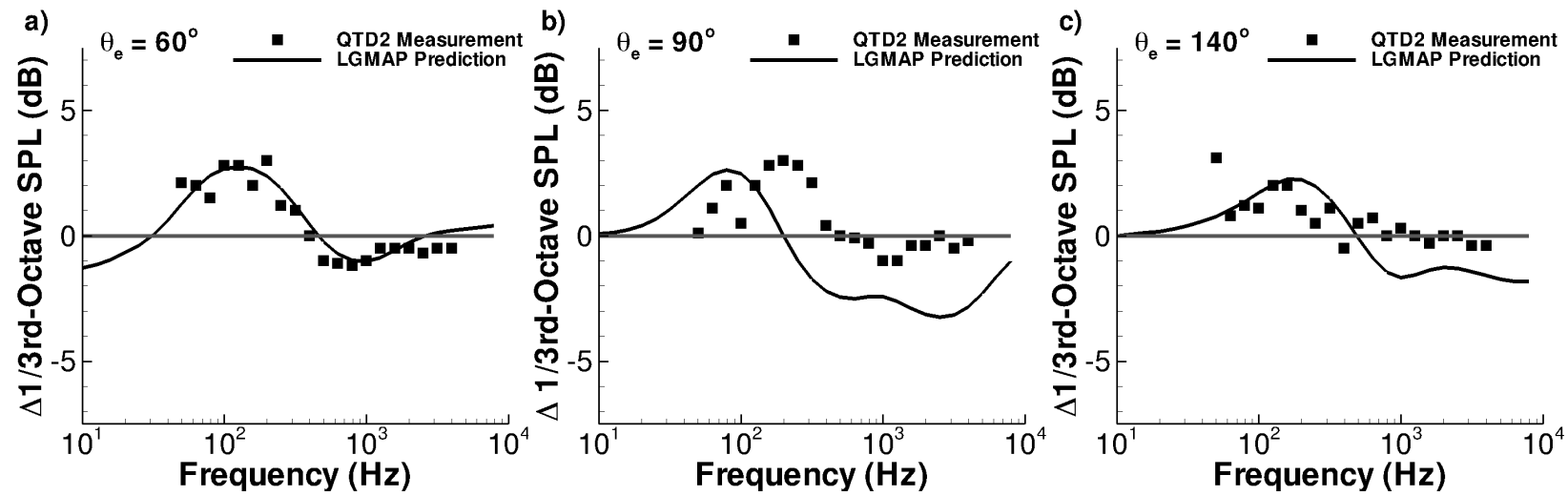

Figure 10. QTD2 flight measurements of landing gear noise with a toboggan fairing installed on the main gear compared to LGMAP predictions at emission angles of (a) $60^{\circ}$, (b) $90^{\circ}$, and (c) $140^{\circ}$. The predicted SPL at $1 / 3$-octave center frequency of $1000 \mathrm{~Hz}$ is (a) $67.3 \mathrm{~dB}$ at $60^{\circ}$, (b) $59.4 \mathrm{~dB}$ at $90^{\circ}$, and (c) $66.1 \mathrm{~dB}$ at $140^{\circ}$. Symbols represent measurements and lines are LGMAP predictions.

\section{Conclusions}

A unique method for predicting the noise due to a landing gear configuration change has been presented. Predictions using the Landing Gear Model and Acoustic Prediction (LGMAP) code were compared to measurements performed in the Quiet Flow Facility (QFF) at NASA Langley for three landing gear geometries. This included a baseline case, baseline without the landing gear door, and baseline with a toboggan fairing. The LGMAP code was shown to predict the noise magnitude, spectral shape, and directivity well for all three configurations. These predictions demonstrate LGMAP's unique ability to predict noise from configuration changes allowing for the prediction of noise from future low-noise landing gear designs.

The LGMAP geometries used in the comparisons with QFF measurements were scaled and compared to flight test data acquired during the Quiet Technology Demonstrator 2 program. LGMAP predictions of the noise spectral shape from the landing gear matched well with aircraft measurements at three directivity angles. Comparisons of measured and predicted noise from the baseline and toboggan faired gear showed that LGMAP was able to predict some of the trends in the noise caused by the toboggan fairing.

Future work on using LGMAP as a prediction method to predict the noise caused by configuration changes must be coupled with a flow field prediction or measurement that can predict the flow change caused by a configuration change. Also, much of LGMAP is still empirically based with strengths, spectral shapes, and directivities of the acoustic elements set by calibrated coefficients. While these coefficients have evolved over time, as more measurements of landing gear noise is released, a method must be researched for discerning their physics based mechanisms.

\section{Acknowledgements}

The author would like to acknowledge Kenneth Brentner of The Pennsylvania State University for granting use of the LGMAP code and William Humphreys of NASA Langley for providing the QFF measurements.

\section{References}

\footnotetext{
1 "Noise Standards: Aircraft Type and Airworthiness Certification. FAR pt. 36," Tech. rep., Federal Aviation Administation, June 1974, Consolidated Reprint Aug. 12, 1985.

${ }^{2}$ Ginevsky, A. S., Vlasov, Y. V., and Karavosov, R. K., Acoustic Control of Turbulent Jets, Springer-Verlag, New York City, New York, 2004.
} 
${ }^{3}$ Lasagna, P. L., Mackall, K. G., Burcham Jr., F. W., and Putnam, T. W., "Landing Approach Airframe Noise Measurements and Analysis," NASA/TP 1602, NASA, January 1980.

${ }^{4}$ Nark, D. M., Burley, C. L., Tinetti, A., and Rawls Jr., J. W., "Initial Integration of Noise Prediction Tools for Acoustic Scattering Effects," May 5-7 2008, AIAA Paper No. 2008-2996, $14^{\text {th }}$ AIAA/CEAS Aeroacoustcs Conference (29 ${ }^{\text {th }}$ AIAA Aeroacoustics Conference).

${ }^{5}$ Crighton, D. G., Airframe Noise, Acoustical Society of America, Woodbury, NY, 1995.

${ }^{6}$ Lilley, G. M., "The Prediction of Airframe Noise and Comparison with Experiment," Journal of Sound and Vibration, Vol. 239, No. 4, 2001, pp. 849-859.

${ }^{7}$ Fink, M. R., "Noise Component Method for Airframe Noise," AIAA Journal of Aircraft, Vol. 16, No. 10, October 1979, pp. 659-665.

${ }^{8}$ Ffowcs Williams, J. E. and Hall, L. H., "Aerodynamic sound generation by turbulent flow in the vicinity of a scattering half-plane," Journal of Fluid Mechanics, Vol. 40, 1970, pp. 657-670.

${ }^{9}$ Hardin, J. C., "Noise Radiation from the Side Edges of Flaps," AIAA Journal, Vol. 18, No. 5, May 1980, pp. 549-552.

${ }^{10}$ Brooks, T. F., Pope, S. D., and Marcolini, M. A., "Aifoil self-noise and prediction," NASA RP 1218, NASA, July 1989.

${ }^{11}$ Guo, Y., "Airframe Noise Prediction by Acoustic Analogy," NASA Contract NAS1-00086, The Boeing Corporation, Boeing Phantom Works, Langley Research Center, Hampton, Virginia 23681-2199, February 2004.

${ }^{12}$ Guo, Y., "A Study on Local Flow Variations for Landing Gear Noise Research," May 5-7 2008, AIAA Paper No. 20082915, $14^{\text {th }}$ AIAA/CEAS Aerodynamics Conference (29th AIAA Aeroacoustics Conference).

${ }^{13}$ Stoker, R. W., "Landing Gear Noise Test Report," NASA Contractor Informal Report NAS1-97040, Boeing, 1999.

${ }^{14}$ Kipersztok, O. and Senguptat, G., "Flight Test of the 747-JT9D for Airframe Noise," AIAA Journal of Aircraft, Vol. 19, No. 12, December 1982, pp. 1061-1069.

${ }^{15}$ Stoker, R. W. and Sen, R., "An Experimental Investigation of Airframe Noise Using a Model-Scale Boeing 777," January 8-11 2001, AIAA Paper No. A01-16784, 39 ${ }^{\text {th }}$ AIAA Aerospace Sciences Meeting \& Exhibit.

${ }^{16}$ Lockard, D. P., Khorrami, M. R., and Li, F., "High Resolution Calculation of a Simplified Landing Gear," May 10-13 2004, AIAA Paper No. 2004-2887, 10 th AIAA/CEAS Aeroacoustics Conference.

${ }^{17}$ Herkes, W. H., Olsen, R. F., and Uellenberg, S., "The Quiet Technology Demonstrator Program: Flight Validation of Airplane Noise-Reduction Concepts," May 8-10 2006, AIAA Paper No. 2006-2720, $12^{\text {th }}$ AIAA/CEAS Aeroacoustics Conference (27 $7^{\text {th }}$ AIAA Aeroacoustics Conference).

${ }^{18}$ Ravetta, P. A., Burdisso, R. A., Ng, W. F., Khorrami, M. R., and Stoker, R. W., "Screening Of Potential Noise Control Devices At Virginia Tech For Qtd Ii Flight Test," May 21-23 2007, AIAA Paper No. 2007-3455, $13^{\text {th }}$ AIAA/CEAS Aeroacoustics Conference (28 ${ }^{\text {th }}$ AIAA Aeroacoustics Conference).

${ }^{19}$ Remillieux, M. C., Camargo, H. E., Ravetta, P. A., Burdisso, R. A., and Ng, W. F., "Noise Reduction of a Model-Scale Landing Gear Measured in the Virginia Tech Aeroacoustic Wind Tunnel," May 5-7 2008, AIAA Paper No. 2008-2818, 14 ${ }^{\text {th }}$ AIAA/CEAS Aeroacoustcs Conference (29th AIAA Aeroacoustics Conference).

${ }^{20}$ Elkoby, R., Brusniak, L., Stoker, R. W., Khorrami, M. R., Abeysinghe, A., and Moe, J. W., "Airframe Noise Results from the QTD II Flight Test Program," May 21-23 2007, AIAA Paper No. 2007-3457, $13^{\text {th }}$ AIAA/CEAS Aeroacoustics Conference (28 $8^{t h}$ AIAA Aeroacoustics Conference).

${ }^{21}$ Humphreys, W. M. and Brooks, T. F., "Noise Spectra and Directivity For a Scale-Model Landing Gear," May 21-23 2007, AIAA Paper No. 2007-3458, $13^{\text {th }}$ AIAA/CEAS Aeroacoustics Conference (28 ${ }^{\text {th }}$ AIAA Aeroacoustics Conference).

${ }^{22}$ Dobrzynski, W. M., Schning, B., Chow, L. C., Wood, C., Smith, M., and Seror, C., "Design and Testing of Low Noise Landing Gears," May 23-25 2005, AIAA Paper No. 2005-3008, $11^{\text {th }}$ AIAA/CEAS Aeroacoustics Conference (26 ${ }^{\text {th }}$ AIAA Aeroacoustics Conference).

${ }^{23}$ Dobrzynski, W., Chow, L. C., Smith, M., Boillot, A., Dereure, O., and Molin, N., "Experimental Assessment of Low Noise Landing Gear Component Design," May 11-13 2009, AIAA Paper No. 2009-3276, $15^{\text {th }}$ AIAA/CEAS Aeroacoustics Conference $\left(30^{t h}\right.$ AIAA Aeroacoustics Conference).

${ }^{24}$ Fink, M. R., "Component Method for Airframe Noise," Tech. rep., Federal Aviation Administration, 1977, FAA-RD-7729. Available from DTIC as AD A039 664.

${ }^{25}$ Guo, Y., "Empirical Prediction of Aircraft Landing Gear Noise," NASA CR NASA/CR-2005-213780, The Boeing Corporation, Boeing Phantom Works, Langley Research Center,Hampton, Virginia 23681-2199, July 2005.

${ }^{26}$ Burley, C. L., Brooks, T. F., and William M. Humphreys, J., "ANOPP Landing Gear Noise Prediction Comparisons to Model-Scale Data," May 21-23 2007, AIAA Paper No. 2007-3459, $13^{\text {th }}$ AIAA/CEAS Aeroacoustics Conference (28 ${ }^{t h}$ AIAA Aeroacoustics Conference).

${ }^{27}$ Smith, M. G., "Prediction Method for Aerodynamic Noise from Aircraft Landing Gear," June 2-4 1998, AIAA Paper No. 1998-2228, $4^{\text {th }}$ AIAA/CEAS Aeroacoustcs Conference (19 ${ }^{\text {th }}$ AIAA Aeroacoustics Conference).

${ }^{28}$ Smith, M. G. and Chow, L. C., "Validation of a Prediction Model for Aerodynamic Noise from Aircraft Landing Gear," June 17-19 2002, AIAA Paper No. 2002-2581, $8^{\text {th }}$ AIAA/CEAS Aeroacoustics Conference and Exhibit.

${ }^{29}$ Lopes, L. V., Brentner, K. S., Morris, P. J., Lilley, G. M., and Lockard, D. P., "Complex Landing Gear Noise Prediction Using a Simple Toolkit," January 10-13 2005, AIAA Paper No. 2005-1202, 43 ${ }^{\text {rd }}$ AIAA Aerospace Sciences Meeting and Exhibit.

${ }^{30}$ Lopes, L. V., Brentner, K. S., Morris, P. J., and Lockard, D. P., "Increased Fidelity in Prediction Methods for Landing Gear Noise," May 8-10 2006, AIAA Paper No. 2006-2624, $12^{\text {th }}$ AIAA/CEAS Aeroacoustics Conference (27 $7^{\text {th }}$ AIAA Aeroacoustics Conference).

${ }^{31}$ Lopes, L. V., Brentner, K. S., and Morris, P. J., "Airframe Noise Prediction with Installed Landing Gear for a Complete Aircraft," May 11-13 2009, AIAA Paper No. 2009-3155, $15^{\text {th }}$ AIAA/CEAS Aeroacoustics Conference (30 ${ }^{t h}$ AIAA Aeroacoustics Conference).

${ }^{32}$ Lopes, L. V., A New Approach to Complete Aircraft Landing Gear Noise Prediction, Ph.D. thesis, The Pennsylvania State University, University Park, Pennsylvania, December 2009.

15 of 16 
${ }^{33}$ Moriarty, P., Guidati, G., and Migliore, P., "Prediction of Turbulent Inflow and Trailing-Edge Noise for Wind Turbines," May 23-25 2005, AIAA paper No. 2005-2881, $11^{\text {th }}$ AIAA/CEAS Aeroacoustics Conference (26 ${ }^{\text {th }}$ AIAA Aeroacoustics Conference).

${ }^{34}$ Drela, M. and Youngren, H., XFOIL 6.94 User Guide, Massachusetts Institute of Technology, Cambridge, Massachusetts, 2001.

${ }^{35}$ Brooks, T. F. and Humphreys, W. M., "A Deconvolution Approach for the Mapping of Acoustic Sources (DAMAS) Determined from Phased Microphone Arrays," May 10-12 2004, AIAA Paper No. 2004-2954, 10 ${ }^{\text {th }}$ AIAA/CEAS Aeroacoustics Conference.

${ }^{36}$ Humphreys, W. M. and Brooks, T. F., "Noise Spectra and Directivity for a Scale-Model Landing Gear," International Journal of Aeroacoustics, Vol. 8, No. 5, July 2009, pp. 409-444.

${ }^{37}$ Brusniak, L., Underbrink, J. R., and Stoker, R. W., "Acoustic Imaging of Aircraft Noise Sources Using Large Aperture Phased Arrays," May 8-10 2006, AIAA Paper No. 2006-2715, $12^{\text {th }}$ AIAA/CEAS Aeroacoustics Conference (27 ${ }^{\text {th }}$ AIAA Aeroacoustics Conference). 